\title{
Common medications used by patients with type 2 diabetes mellitus: what are their effects on the lipid profile?
}

\author{
Paul D. Rosenblit ${ }^{1,2^{*}}$
}

\begin{abstract}
Dyslipidemia is the most fundamental risk factor for atherosclerotic cardiovascular disease (ASCVD). In clinical practice, many commonly prescribed medications can alter the patient's lipid profile and, potentially, the risk for ASCVD_either favorably or unfavorably. The dyslipidemia observed in type 2 diabetes mellitus (T2DM) can be characterized as both ominous and cryptic, in terms of unrecognized, disproportionately elevated atherogenic cholesterol particle concentrations, in spite of deceptively and relatively lower levels of low-density lipoprotein cholesterol (LDL-C). Several factors, most notably insulin resistance, associated with the unfavorable discordance of elevated triglyceride (TG) levels and low levels of high-density lipoprotein cholesterol (HDL-C), have been shown to correlate with an increased risk/ number of ASCVD events in patients with T2DM. This review focuses on known changes in the routine lipid profile ( $L D L-C, T G s$, and HDL-C) observed with commonly prescribed medications for patients with T2DM, including antihyperglycemic agents, antihypertensive agents, weight loss medications, antibiotics, analgesics, oral contraceptives, and hormone replacement therapies. Given that the risk of ASCVD is already elevated for patients with T2DM, the use of polypharmacy may warrant close observation of overall alterations through ongoing lipid-panel monitoring. Ultimately, the goal is to reduce levels of atherogenic cholesterol particles and thus the patient's absolute risk.
\end{abstract}

Keywords: Atherosclerosis, Dyslipidemia, HDL cholesterol, LDL cholesterol, Triglycerides, Type 2 diabetes mellitus, Cardiovascular risk factors, Polypharmacy

\section{Background}

Atherosclerotic cardiovascular disease (ASCVD) is a major cause of premature death worldwide, accounting for $37 \%$ of the 16 million annual deaths caused by noncommunicable diseases in those younger than 70 years of age [1]. Atherosclerosis is a process that begins early in life and its progression is dependent on the presence and magnitude of risks [2,3]. Atherosclerosis is the major cause of morbidity and mortality in patients with type 2 diabetes mellitus (T2DM) [4] for both men [5] and women [6]. In 2013, the worldwide, multidisciplinary, academic Residual Risk Reduction Initiative identified atherogenic dyslipidemia as a key contributor

\footnotetext{
*Correspondence: pdrosenblit@yahoo.com

${ }^{1}$ Diabetes/Lipid Management \& Research Center, 18821 Delaware St, Suite 202, Huntington Beach, CA 92648, USA

Full list of author information is available at the end of the article
}

to lipid-related cardiovascular $(\mathrm{CV})$ risk in patients with insulin resistance [7]. In patients with either type 1 diabetes mellitus (T1DM) or T2DM, all-cause mortality and ASCVD mortality increase with worsening glycemic control. However, even with good glycemic control (i.e. glycated hemoglobin $[\mathrm{A} 1 \mathrm{C}]<7.0 \%$ ), these patients have twice the mortality risk compared to the general population $[8,9]$. Analyses of large databases demonstrate that mortality associated with a history of myocardial infarction (MI), stroke, or diabetes (without MI or stroke) is equivalent, and patients with diabetes plus a history of $\mathrm{MI}$ and/or stroke have multiplicative (extreme) risk [10].

MI and cerebrovascular incidents are most commonly triggered by the rupture of an unstable/vulnerable atherosclerotic plaque [11]. Atherosclerosis is a lipid-driven inflammatory disorder of the arterial wall caused by cholesterol deposition in the intima-media of vessels supplying cardiac or brain tissue [12]. Elevated 
concentrations of atherogenic lipid particles that carry cholesterol in the blood represent the fundamental risk factor for ASCVD [3, 13, 14]. This is especially true in the diabetes population, which is enriched with dyslipidemia of insulin resistance $[15,16]$. The cholesterol contained within apolipoprotein B (apo B) particles, also referred to as non-high-density lipoprotein cholesterol (non-HDL-C), is strongly associated with the pathogenesis of atherosclerosis [3]. Non-HDL-C is calculated as total cholesterol minus HDL-C, and includes very-low-density lipoprotein (VLDL), VLDL remnants, intermediate-density lipoprotein, chylomicrons, chylomicron remnants, lipoprotein(a), and the predominant cholesterol-carrying lipoprotein, low-density lipoprotein cholesterol (LDL-C). Elevated levels of atherogenic lipoprotein particles containing both cholesterol and triglycerides (TGs) can be attributed to a number of genetic disorders, common diseases, and altered metabolic states (e.g. hypothyroidism, pregnancy, menopause, diabetes, chronic kidney disease [CKD], nephrotic syndrome, and human immunodeficiency virus [HIV] infection). Furthermore, risks such as hyperglycemia, hypertension, and obesity, as well as lifestyle factors (e.g. tobacco use, unhealthy diet, physical inactivity, and excessive use of alcohol) can accelerate the lipid-driven atherosclerosis process $[1,3]$.

Importantly, many non-lipid-specific medications commonly prescribed in primary care can also have offtarget, unintended, or pleiotropic effects on the lipid profile and may, therefore, potentially positively or negatively influence the risk of ASCVD [17-20].

The implications of changes in lipid levels might become a particularly important issue in patients with T2DM if one assumes stability of lipids on current therapies. The risk of cardiovascular disease (CVD) has been shown to increase with the duration and an earlier onset of T2DM [21]. Additionally, many patients with T2DM will not only experience atherogenic dyslipidemia [4, $16,22]$, but usually will also experience one or a combination of additional accelerating risk factors associated with ASCVD, including hypertension, CKD, obesity, and insulin resistance/hyperinsulinemia [23, 24]. Insulin resistance, prediabetes, DM, and CKD are frequently associated with varying degrees of dyslipidemia (i.e. elevated TG levels, decreased HDL-C levels, and low or below-normal LDL-C levels). These common, often subtle, lipid profile findings are highly atherogenic because of the presence of elevated apo B particles of small, dense LDL particles (LDL-P) and TG-rich VLDL and their remnants, even when LDL-C or non-HDL-C are at relatively lower or even normal levels; this combination is often referred to as unfavorable discordance. Unlike the general population, in this setting, where the population (i.e. insulin resistance, obesity, prediabetes, metabolic syndrome, high TG levels, low HDL-C levels, T2DM) is enriched with unfavorable discordance, apo B or LDL-P concentrations are much more predictive as biomarkers of ASCVD risk [4, 13, 14, 16, 24, 25]. Dyslipidemia associated with insulin resistance is often exacerbated if glucose levels are not well controlled [25].

Although absolute risk varies as a spectrum among a group of individuals, the National Lipid Association (NLA) currently defines only two risk categories for patients with diabetes: very high risk and high risk [3]. The very-high-risk category for diabetes includes not only secondary prevention patients (i.e. those with prior clinical ASCVD events) but also primary prevention patients with $\geq 2$ other major risk factors: low HDL-C $(<40 \mathrm{mg} / \mathrm{dL}[<1.04 \mathrm{mmol} / \mathrm{L}])$, hypertension $(\geq 140 / 90 \mathrm{mmHg})$ or on antihypertensive medication, smoking, family history of premature coronary heart disease (CHD) in a male first-degree relative $<55$ years of age or in a female first-degree relative $<65$ years of age, age (men $\geq 45$ years of age; women $\geq 55$ years of age), or evidence of end-organ damage (albumin-to-creatinine ratio $>30 \mathrm{mg} / \mathrm{g}$ [ $>3.39 \mathrm{mg} / \mathrm{mmol}$ ], CKD [estimated glomerular filtration rate $>60 \mathrm{~mL} / \mathrm{min} / 1.73 \mathrm{~m}^{2}$ ], or retinopathy). The high-risk category for diabetes includes primary prevention patients (i.e. no recognized prior clinical ASCVD events) with $\leq 1$ other major ASCVD risk factor and no evidence of end-organ damage. While not defining lower limits for atherogenic cholesterol goals, for very-high-risk patients with diabetes, the specific lipid targets of non-HDL-C, LDL-C, and apo B, have treatment goals of $<100 \mathrm{mg} / \mathrm{dL}[<2.59 \mathrm{mmol} / \mathrm{L}],<70 \mathrm{mg} / \mathrm{dL}$ $[<1.81 \mathrm{mmol} / \mathrm{L}]$, and $<80 \mathrm{mg} / \mathrm{dL}[<0.80 \mathrm{~g} / \mathrm{L}]$, respectively. For high-risk patients with diabetes, the specific lipid targets of non-HDL-C, LDL-C, and apo B have treatment goals of $<130 \mathrm{mg} / \mathrm{dL}[<3.37 \mathrm{mmol} / \mathrm{L}],<100 \mathrm{mg} / \mathrm{dL}$ $[<2.59 \mathrm{mmol} / \mathrm{L}]$, and $<90 \mathrm{mg} / \mathrm{dL}[<0.90 \mathrm{~g} / \mathrm{L}]$, respectively [3]. The American Association of Clinical Endocrinologists (AACE) currently also describes only two categories of risk for patients with diabetes. Targeted atherogenic cholesterol particle goals (i.e. non-HDL-C, LDL-C, apo B) are similar to those of the NLA, with the added targeted LDL-P goal of $<1000 \mathrm{nmol} / \mathrm{L}$ for very-high-risk and $<1200 \mathrm{nmol} / \mathrm{L}$ for high-risk patients, consistent with the population percentile cut-points [26] and equivalent to apo $\mathrm{B}<80 \mathrm{mg} / \mathrm{dL}[<0.80 \mathrm{~g} / \mathrm{L}]$ and $<90 \mathrm{mg} / \mathrm{dL}[0.9 \mathrm{~g} / \mathrm{L}]$, respectively (Table 1) [27]. Recommendations for dyslipidemia management in diabetes, utilizing lifestyle changes and lipid-lowering agents (e.g. statins, possibly in combination with a fibrate, niacin, omega- 3 fatty acids, or ezetimibe) that target atherogenic cholesterol particles to specific goals determined by absolute risk, have recently been published $[3,7,27,28]$. 
Table 1 AACE lipid targets for patients with T2DM (Reprinted with permission from the American Association of Clinical Endocrinologists $\odot 2016$ AACE [27])

\begin{tabular}{lll}
\hline Lipid & $\begin{array}{l}\text { High-risk patients } \\
\text { (T2DM but no other } \\
\text { major risk and/or age } \\
<\mathbf{4 0} \text { years) }\end{array}$ & $\begin{array}{l}\text { Very-high-risk patients } \\
\text { (T2DM plus } \geq 1 \text { major } \\
\text { ASCVD risk or ASCVD }\end{array}$ \\
\hline LDL-C & $<100 \mathrm{mg} / \mathrm{dL}$ & \\
Non-HDL-C & $<130 \mathrm{mg} / \mathrm{dL}$ & $<70 \mathrm{mg} / \mathrm{dL}$ \\
& {$[<3.37 \mathrm{mmol} / \mathrm{L}]$} & $<100 \mathrm{mg} / \mathrm{dL}$ \\
TGS & $<150 \mathrm{mg} / \mathrm{dL}$ & {$[<2.59 \mathrm{mmol} / \mathrm{L}]$} \\
& {$[<1.69 \mathrm{mmol} / \mathrm{L}]$} & $<150 \mathrm{mg} / \mathrm{dL}$ \\
TC/HDL-C & $<3.5$ & {$[<1.69 \mathrm{mmol} / \mathrm{L}]$} \\
Apo B & $<90 \mathrm{mg} / \mathrm{dL}[<0.90 \mathrm{~g} / \mathrm{L}]$ & $<3.0$ \\
LDL-P & $<1200 \mathrm{nmol} / \mathrm{L}$ & $<1000 \mathrm{mg} / \mathrm{dL}[<0.80 \mathrm{~g} / \mathrm{L}]$ \\
\end{tabular}

AACE American Association of Clinical Endocrinologists, apo B apolipoprotein B, $A S C V D$ atherosclerotic cardiovascular disease, $H D L-C$ high-density lipoprotein cholesterol, $L D L$-C low-density lipoprotein cholesterol, LDL-P low-density lipoprotein particle, T2DM type 2 diabetes mellitus, TC total cholesterol, $T G$ triglyceride

a Hypertension, family history of ASCVD, low HDL-C, smoking

${ }^{\mathrm{b}}$ Even more intensive therapy might be warranted

This review aims to provide a simplified qualitative overview of selected commonly prescribed medications for patients with T2DM and their effects on the routine lipid profile (i.e. TGs, HDL-C, and LDL-C). This review does not address the use of standard lipid-lowering agents in T2DM, since these agents have been discussed in detail in recent guidelines [7, 28]. Rather, this review focuses on drugs indicated for the management of hyperglycemia (i.e. antidiabetic agents), as well as other commonly used medications in patients with T2DM, including antihypertensive agents, weight loss medications, antibiotics, analgesics, oral contraceptives, and hormone replacement therapy (HRT).

\section{Effects of polypharmacy on the routine lipid profile}

Many non-lipid-specific medications widely used in clinical practice have been associated with changes in the lipid profile [17-19]. These changes are summarized in Table 2.

To clarify, no studies have clearly demonstrated that raising the cholesterol content of HDL-C particles or lowering TG levels translate to a reduction in ASCVD risk. Furthermore, to demonstrate a statistically significant reduction in ASCVD risk, clinical trials investigating the effects of lowering LDL-C levels have shown that a threshold betweengroup difference in LDL-C levels, usually exceeding $25 \mathrm{mg}$ / $\mathrm{dL}[0.65 \mathrm{mmol} / \mathrm{L}]$, is required in the typical 3- to 5 -year studies. Therefore, it should be remembered that, despite significant clinical effects of some medications on the lipid profile, little is known about the clinical relevance of these changes. However, effects on the lipid profile, whether significant or nominal for any single agent, should not be considered in isolation, since most patients will be taking multiple medications from various classes to treat multiple comorbidities. For this reason, it is important to observe the overall changes governing the ultimate management of dyslipidemia to reduce the ASCVD risk.

\section{Antihyperglycemic agents}

Guidelines and algorithms for the treatment of hyperglycemia recommend monotherapy and/or combinations of available agents to achieve or maintain blood glucose at levels that are as close to normal as possible, without increasing the patient's risk of hypoglycemia [29-31]. These agents may have direct or indirect effects on a patient's lipid profile. An overview of the qualitative effects of the hypoglycemic and antihyperglycemic agents described in the AACE algorithm [27] on the lipid profile is provided in Table 2 .

\section{Metformin}

Current guidelines list metformin, a biguanide, as a firstline oral antihyperglycemic therapy, unless it is contraindicated or not tolerated [29-31]. While its mechanism of action is not well understood, metformin clearly has an inhibitory effect on gluconeogenesis and hepatic glucose output and, contrary to previous opinions, appears not to have any substantial insulin-sensitizing effect in muscle [32]. Metformin has been associated with small increases in HDL-C levels [33] that may be more pronounced in Whites and African Americans than in Hispanic populations [34]. Metformin is also associated with decreases in TG, total cholesterol, and LDL-C levels [33]. The TG-lowering effect was associated with its glycemic control outcomes. Some reductions in total cholesterol and LDL-C levels were observed independent of glycemic control, but these nominal changes are not considered clinically relevant to ASCVD endpoints. In the United Kingdom Prospective Diabetes Study (UKPDS), metformin reduced the risk of MI more than sulfonylureas (SUs) or insulin in a small cohort of obese patients with T2DM [35]. The Study on the Prognosis and Effect of Antidiabetic Drugs on Type 2 Diabetes Mellitus with Coronary Artery Disease (SPREAD-DIMCAD) reported that 3 years of metformin treatment was associated with significantly lower CVD risk after an additional 2 years of post-drug followup compared to glipizide in 304 patients with T2DM and coronary artery disease [36].

\section{Thiazolidinediones}

Thiazolidinediones (TZDs), such as pioglitazone and rosiglitazone, stimulate peroxisome proliferator-activated receptors and have differential effects on the basic constituents of the lipid profile. Both pioglitazone and 
Table 2 Effects of commonly used medications on the lipid profile

\begin{tabular}{|c|c|c|c|c|c|}
\hline Medication type/class & Compound & TGs & HDL-C & LDL-C & Reference(s) \\
\hline \multicolumn{6}{|l|}{ Antihyperglycemic } \\
\hline Biguanide & Metformin & $\downarrow$ & Slight $\uparrow$ & $\downarrow$ & {$[23,44]$} \\
\hline \multirow[t]{2}{*}{ TZD } & Pioglitazone & $\downarrow$ & $\uparrow$ & $\uparrow$ & {$[23,38,44]$} \\
\hline & Rosiglitazone & $\uparrow$ & $\uparrow$ & $\uparrow$ & {$[23,38,44]$} \\
\hline \multirow[t]{3}{*}{ SU } & Glibenclamide & $\downarrow / \leftrightarrow$ & $\leftrightarrow$ & $\downarrow / \leftrightarrow$ & {$[23,44]$} \\
\hline & Gliclazide & $\downarrow$ & $\leftrightarrow$ & $\leftrightarrow$ & {$[23,44]$} \\
\hline & Glimepiride & $\leftrightarrow$ & $\leftrightarrow$ & $\leftrightarrow$ & {$[23,44]$} \\
\hline \multirow[t]{4}{*}{ DPP-4 inhibitor } & Sitagliptin & $\downarrow$ & $\leftrightarrow$ & $\leftrightarrow$ & {$[52]$} \\
\hline & Vildagliptin & $\downarrow$ & $\leftrightarrow$ & $\leftrightarrow / \downarrow$ & {$[54,58]$} \\
\hline & Saxagliptin & $\leftrightarrow$ & $\leftrightarrow$ & $\leftrightarrow$ & {$[152]$} \\
\hline & Alogliptin & $\downarrow$ & $\leftrightarrow$ & $\downarrow$ & {$[53]$} \\
\hline \multirow[t]{2}{*}{ GLP-1 receptor agonist } & Exenatide & $\downarrow$ & $\uparrow$ & $\downarrow$ & {$[23,65,66]$} \\
\hline & Liraglutide & $\downarrow$ & $\uparrow$ & $\downarrow$ & {$[23,66]$} \\
\hline \multirow[t]{3}{*}{ SGLT2 inhibitor } & Canagliflozin & $\downarrow$ & $\uparrow$ & $\uparrow$ & {$[73]$} \\
\hline & Dapagliflozin & $\leftrightarrow$ & $\uparrow$ & $\uparrow$ & {$[71]$} \\
\hline & Empagliflozin & $\leftrightarrow$ & Slight $\uparrow$ & $\uparrow$ & {$[74]$} \\
\hline \multirow[t]{2}{*}{ a-Glucosidase inhibitor } & Acarbose & $\leftrightarrow / \downarrow$ & $\leftrightarrow / \uparrow$ & $\leftrightarrow$ & {$[37,86,87]$} \\
\hline & Miglitol & $\leftrightarrow$ & $\leftrightarrow$ & $\leftrightarrow$ & {$[86]$} \\
\hline Dopamine D2 receptor agonist & Bromocriptine-QR & $\downarrow$ & $\leftrightarrow$ & $\leftrightarrow$ & {$[83,84]$} \\
\hline Bile acid sequestrant & Colesevelam & $\leftrightarrow / \uparrow / \uparrow \uparrow$ & Slight $\uparrow$ & $\downarrow \downarrow$ & {$[77-79]$} \\
\hline Insulin & & $\downarrow$ & $\uparrow$ & $\leftrightarrow$ & {$[44,91]$} \\
\hline \multicolumn{6}{|l|}{ Antihypertensive } \\
\hline Thiazide diuretic & & $\uparrow$ & $\leftrightarrow$ & $\uparrow$ & {$[95,153]$} \\
\hline ACE inhibitor & & $\leftrightarrow / \downarrow$ & $\leftrightarrow / \uparrow$ & $\leftrightarrow / \downarrow$ & {$[101,102,104,154]$} \\
\hline ARB & & $\downarrow$ & $\uparrow / \leftrightarrow^{\mathrm{a}}$ & $\downarrow$ & {$[95,105]$} \\
\hline Older-generation $\beta$-blocker & e.g. propranolol & $\uparrow$ & $\downarrow$ & $\leftrightarrow$ & {$[17,41]$} \\
\hline Newer-generation $\beta$-blocker & e.g. nebivolol & $\leftrightarrow$ & $\leftrightarrow$ & $\downarrow$ & {$[93,108]$} \\
\hline \multicolumn{6}{|l|}{ Anti-obesity } \\
\hline & Orlistat & $\downarrow / \leftrightarrow$ & $\downarrow / \leftrightarrow$ & $\downarrow$ & [110-113] \\
\hline & Lorcaserin & $\downarrow / \leftrightarrow$ & $\uparrow / \leftrightarrow$ & $\downarrow / \leftrightarrow$ & [114-117] \\
\hline & Phentermine/topiramate & $\downarrow$ & $\uparrow$ & $\downarrow$ & {$[122,126-128]$} \\
\hline & Naltrexone/bupropion & $\downarrow$ & $\uparrow$ & $\downarrow / \leftrightarrow$ & [118-121, 123-125] \\
\hline \multicolumn{6}{|l|}{ Antibiotics } \\
\hline & Metronidazole & $\leftrightarrow$ & $\leftrightarrow$ & $\downarrow$ & {$[129,130]$} \\
\hline & Ciprofloxacin & $\leftrightarrow$ & $\uparrow$ & $\leftrightarrow$ & [130] \\
\hline \multicolumn{6}{|l|}{ Analgesic } \\
\hline NSAIDs & e.g. ibuprofen, naproxen & $\leftrightarrow$ & $\leftrightarrow$ & $\leftrightarrow$ & {$[131,134]$} \\
\hline Aspirin & & $\downarrow$ & $\leftrightarrow$ & $\downarrow$ & {$[131,134]$} \\
\hline \multicolumn{6}{|l|}{ Contraceptive } \\
\hline Oral contraceptives with second-generation progestogens & e.g. levonorgestrel & $\uparrow$ & $\downarrow$ & $\uparrow$ & {$[17,141]$} \\
\hline Oral contraceptives with third-generation progestogens & e.g. desogestrel & $\uparrow$ & $\uparrow$ & $\downarrow$ & {$[17,141]$} \\
\hline \multicolumn{6}{|l|}{ HRT } \\
\hline Estrogen monotherapy & & - & $\uparrow$ & $\downarrow$ & [143] \\
\hline Transdermal 17ß-estradiol & & $\leftrightarrow$ & $\leftrightarrow$ & $\leftrightarrow$ & [143] \\
\hline Oral estrogen/DMPA & & - & - & - & {$[145,146]$} \\
\hline \multicolumn{6}{|l|}{ Other common medications } \\
\hline Glucocorticoids & e.g. prednisone & $\uparrow$ & $\uparrow$ & $\uparrow$ & {$[95,147]$} \\
\hline
\end{tabular}


Table 2 continued

\begin{tabular}{llllll}
\hline Medication type/class & Compound & TGs & HDL-C & LDL-C & Reference(s) \\
\hline Vitamins & Vitamin D & $\leftrightarrow$ & Slight $\uparrow$ & $\leftrightarrow$ & {$[148]$} \\
& Vitamin B12 & $\downarrow$ & $\uparrow$ & $\downarrow$ & {$[149]$} \\
& Ascorbic acid (vitamin C) & $\leftrightarrow$ & $\leftrightarrow$ & $\downarrow$ & {$[150,155]$} \\
& PUFAs & $\downarrow$ & $\uparrow$ & $\downarrow$ & {$[151]$}
\end{tabular}

$A C E$ angiotensin-converting enzyme, $A R B$ angiotensin receptor blocker, DMPA depot medroxyprogesterone acetate, DPP-4 dipeptidyl peptidase-4, GLP-1 glucagonlike peptide-1, HDL-C high-density lipoprotein cholesterol, HRT hormone replacement therapy, $L D L-C$ low-density lipoprotein cholesterol, $N S A I D$ nonsteroidal antiinflammatory drug, PUFA polyunsaturated fatty acid, QR quick release, SGLT2 sodium glucose co-transporter 2, SU sulfonylurea, TG triglyceride, TZD thiazolidinedione

a Variable depending on type

$\uparrow$ denotes statistically significant increase; $\leftrightarrow$ denotes no significant change; $\downarrow$ denotes statistically significant decrease; - denotes data not available

rosiglitazone increase LDL-C, non-HDL-C, and HDL-C levels, whereas TG levels are reduced with pioglitazone and increased with rosiglitazone $[37,38]$. In addition, the increase in LDL-C levels has been shown to be smaller, and the increase in HDL-C greater, with pioglitazone than with rosiglitazone [38]. However, careful analysis of associated changes in lipoproteins, particle numbers, and size highlights that the effects of TZDs are more complex than simply affecting the TG or cholesterol content of HDL-C or LDL-C $[39,40]$. Pioglitazone has been shown to decrease LDL-P numbers and to cause more favorable shifts from a predominance of smaller, denser LDL to a larger, more buoyant LDL subtype than rosiglitazone [38], suggesting an overall reduction in the atherogenic phenotype of the lipid profile [41-44]. TZDs have been associated with favorable changes in inflammatory marker levels (i.e. C-reactive protein) and a reduction in visceral fat, but a potentially unfavorable increase in total body weight, partially due to a disproportionate increase in subcutaneous adiposity and fluid retention; the latter carries an increased risk of congestive heart failure in susceptible individuals (i.e. those who already have cardiac dysfunction) [23, 44, 45]. The Prospective Pioglitazone Clinical Trial in Macrovascular Events (PROactive) study $(\mathrm{N}=5238$ patients enrolled at 321 sites across 19 European countries), the only randomized CV study of pioglitazone, demonstrated a favorable but nonsignificant $10 \%$ risk reduction trend $(P=0.095)$ in its primary composite outcome and a significant $16 \%$ decrease $(P=0.027)$ in a secondary composite major adverse cardiac events (MACE) endpoint analysis [46]. The single 5.5-year duration, randomized CV study with rosiglitazone showed no ASCVD benefit [47].

\section{Sulfonylureas}

The hypoglycemic agents SUs (e.g. glibenclamide, gliclazide, and glimepiride) are commonly used as therapy for patients with T2DM. Several studies have shown no significant effects on plasma lipids; a slight decrease in TG levels has been observed, while both HDL-C and
LDL-C levels remain unchanged [44]. However, a recent meta-analysis of data from placebo-controlled trials found that SUs were associated with significant reductions in total cholesterol and decreases in HDL-C levels [37]. Since chronic insulin production leads to increases in weight and an increased risk of hypoglycemia, SUs have been discouraged as early-use agents. However, when used with shorter-acting insulin secretagogues, the glinides (repaglinide and nateglinide) are favored by the AACE algorithm [27]. The dose-dependent hypoglycemic risk of SUs makes them unsuitable for patients with hepatic impairments or moderate to severe renal impairments, especially in elderly patients, as their catabolism and clearance involving the liver and kidney, respectively, are reduced [23, 44]. Analyses of datasets comparing SUs to metformin, which may itself have cardioprotective properties, have raised concerns regarding the $\mathrm{CV}$ safety of this drug class [48]. Analyses of other datasets did not show a CV safety concern regarding the use of SUs [49].

\section{Incretin therapies}

The incretin hormones, glucagon-like peptide-1 (GLP-1) and glucose-dependent insulinotropic peptide, stimulate insulin secretion in a glucose-dependent fashion. GLP-1 suppresses $\alpha$-cell secretion of glucagon via an unknown mechanism. Patients with T2DM have incretin resistance that can be overcome by enhancing incretin levels [50].

Dipeptidyl peptidase-4 inhibitors Dipeptidyl peptidase-4 (DPP-4) inhibitors, such as sitagliptin, saxagliptin, linagliptin, alogliptin, and vildagliptin, nominally enhance endogenous incretin levels, which results in a moderate reduction $(0.6-0.9 \%)$ in A1C. DPP-4 inhibitors are considered weight neutral with modest effects on lipid parameters, including reduction in total cholesterol and TG levels [37]. Sitagliptin has been found to have modest effects on serum lipid levels in general populations of patients with T2DM and to reduce total cholesterol and LDL-C levels in patients with elevated baseline TG levels [23, 51, 52]. Vildagliptin has been shown to decrease total cholesterol and TG 
levels to a greater extent than sitagliptin [51]. In a 1-year retrospective observational study of alogliptin in Japanese patients with T2DM, total cholesterol and LDL-C levels decreased significantly from baseline to 12 months. There was a trend toward lower TG levels over time $(P=0.151$ at 9 months and $P=0.730$ at 12 months) [53]. In studies in normoglycemic subjects, vildagliptin and alogliptin have been shown to decrease postprandial TG, apo B, and remnant lipoprotein cholesterol levels [54, 55]. Similarly, shortterm (4 or 6 weeks) treatment with vildagliptin and sitagliptin has been shown to reduce postprandial TG and apo $B$ levels, possibly by increasing incretin hormone levels and reducing levels of circulating free fatty acids [56, 57]. Furthermore, in a randomized controlled trial in patients with T2DM, Derosa and colleagues observed that, compared with the SU glimepiride, vildagliptin was associated with significantly lower total cholesterol, LDL-C, and TG levels following an oral fat load test [58]. Meta-analysis of studies of dual therapy with a DPP-4 inhibitor plus metformin showed that this combination is associated with small but favorable effects on LDL-C, HDL-C, TG, and total cholesterol levels [59]. Safety studies, which have been of relatively short duration, have failed to demonstrate special ASCVD benefits by DPP-4 inhibitors [60-62].

GLP-1 receptor agonists GLP-1 receptor agonists (RAs) are analogs of the naturally occurring incretin GLP-1 that have a prolonged half-life and, therefore, prolonged action. At pharmacologic doses, GLP-1 RAs increase glucose-dependent insulin secretion, decrease glucose-dependent glucagon secretion, and slow gastric emptying, thereby reducing A1C by $0.8-1.5 \%$. GLP-1 RAs are understood to have minor beneficial effects on CVD risk, which may be related to their effects to promote weight loss and blood pressure reduction $[63,64]$. These effects are maintained when GLP-1 RAs are used as part of dual therapy with metformin [59]. GLP-1 RAs, such as exenatide and liraglutide, are more potent inhibitors of postprandial hyperlipidemia through reduced TG absorption than DPP-4 inhibitors. They also can cause moderate decreases in TG and LDL-C, and increases in HDL-C levels $[23,65,66]$. In an analysis of pooled data from 8 studies of exenatide once weekly, Blonde and colleagues found that patients who lost the most weight with exenatide (quartiles 1 and 2) experienced the greatest reductions in LDL-C, total cholesterol, and TGs, and the greatest increases in HDL-C [67]. The first placebo-controlled, GLP-1 RA, CV safety trial with lixisenatide (Evaluation of Lixisenatide in Acute Coronary Syndrome [ELIXA] trial) showed no specific ASCVD benefit (i.e. neutral effects) [68].

\section{Sodium glucose co-transporter 2 inhibitors}

The sodium glucose co-transporter 2 (SGLT2) inhibitors canagliflozin, dapagliflozin, and empagliflozin are the newest class of antihyperglycemic agents. They lower blood glucose levels by reducing renal glucose reabsorption, resulting in increased urinary glucose excretion. In addition, SGLT2 inhibitors are associated with reductions in body weight and total fat mass (i.e. visceral more than subcutaneous adiposity) and reductions in blood pressure $[69,70]$. Placebo-controlled studies suggest that the SGLT2 inhibitors mediate small $(<8 \%)$ increases in LDL-C [71-74] and HDL-C levels [23, 71-74] and small reductions in TG levels $[71,73,74]$. The clinical relevance of such small changes affecting CVD risk has not yet been shown. The first CV safety trial of this drug class, with a relatively short median duration of 3.1 years, has been completed and has revealed significant reductions in mortality from CV deaths, hospitalization for heart failure, and death from any cause, compared with placebo [75]. The glucuretic effect associated with SGLT2 inhibitors contributed to their real clinical benefits, rather than between-group differences in A1C $(-0.54 \%)$ or nominal lipid effects $(\leq 2 \mathrm{mg} / \mathrm{dL}[\leq 0.05 \mathrm{mmol} / \mathrm{L}]$ difference in $\mathrm{HDL}-\mathrm{C}$ and $\leq 4 \mathrm{mg} / \mathrm{dL}[\leq 0.10 \mathrm{mmol} / \mathrm{L}]$ difference in LDL-C levels) [75].

\section{Colesevelam}

As a highly selective bile acid sequestrant (BAS), colesevelam was first indicated as monotherapy and combination therapy to lower LDL-C levels and CVD risk, and was later indicated for decreasing blood glucose. Its effects on bile acid pool composition, farnesoid $\mathrm{X}$ receptor-mediated alterations in hepatic glucose production and intestinal glucose absorption, influences on peripheral insulin sensitivity, incretin effects, and energy use may all contribute to glucose regulation, with a modest reduction in A1C of $0.5 \%$ [76]. There is no increased risk of hypoglycemia with colesevelam, and therapy results in a reduction in LDL-C levels of $11-18 \%$, a mild increase in TG levels, and a slight increase in HDL-C levels [77-79]. Colesevelam can cause a more marked hypertriglyceridemia in susceptible individuals (usually individuals with baseline moderate hypertriglyceridemia [TG > $200 \mathrm{mg} / \mathrm{dL}$; TG $>2.26 \mathrm{mmol} / \mathrm{L}$ ]) and is best utilized with concomitant statin to improve compensatory VLDL cholesterol (and TG) synthesis. BAS agents have been utilized as monotherapy in the Lipid Research Clinics Coronary Primary Prevention Trial (LRC-CPPT), resulting in a reduction of $9 \%$ in total cholesterol and $11 \%$ in LDL-C levels, and a significant (19\%) risk reduction in $\mathrm{CHD}$ death and/or nonfatal MI. The CHD risk reduction varied with compliance to the $24 \mathrm{~g} /$ day regimen, with a $28 \%$ reduction in LDL-C levels and a $39 \%$ CHD risk reduction observed with the highest compliance [80]. At the maximum dose indicated for colesevelam, reductions in LDL-C levels of 13-18 \% can be expected [77-79]. 
Therefore, combination therapies are recommended since clinically significant reduction of ASCVD risk is not likely to be achieved using monotherapy.

\section{Bromocriptine-QR}

Bromocriptine- $Q R$ is a quick-release formulation of bromocriptine mesylate. When added to antihyperglycemic therapy, bromocriptine-QR can provide significant improvement in glycemic control relative to placebo (0.5-0.8 \% lowering of A1C) [81, 82]. BromocriptineQR simultaneously and significantly reduces fasting and postprandial free fatty acids by $19 \%$ and TG levels by $29 \%$, with no changes in LDL-C or HDL-C levels [83, 84]. In a 52-week safety trial of bromocriptine-QR versus placebo, bromocriptine-QR treatment resulted in a $39 \%$ relative risk reduction in a prespecified composite $\mathrm{CV}$ endpoint $(P=0.0346)$ and a $52 \%$ relative risk reduction in the MACE endpoint $(P<0.05)$ [85].

\section{a-Glucosidase inhibitors}

$\alpha$-Glucosidase inhibitors (AGIs) slow the rate of polysaccharide digestion in the proximal small intestine by inhibiting the gut enzyme that breaks down complex carbohydrates ( $\alpha$-glucosidase), thus delaying polysaccharide absorption. This inhibition dramatically reduces the postprandial glycemic peaks and overall postprandial blood glucose levels, resulting in a moderate $(0.5-0.8 \%)$ reduction in $\mathrm{A} 1 \mathrm{C}$ post-load insulin levels, but not plasma lipids [86]. In a meta-analysis of placebo-controlled trials, acarbose did not significantly alter total cholesterol levels, but was associated with reductions in TG and increases in HDL-C levels [37]. In a multicenter, openlabel, randomized controlled trial of acarbose compared with nateglinide in Chinese patients with T2DM, neither drug had significant effects on total cholesterol, HDLC, LDL-C, or non-HDL-C levels; however, acarbose was associated with significantly greater reductions in fasting and postprandial TG levels compared with nateglinide [87]. In a multicenter, randomized clinical trial, patients with impaired glucose tolerance (a key component of prediabetes) who received acarbose had a $49 \%$ relative risk reduction in the development of $\mathrm{CV}$ events, and a $91 \%$ relative risk reduction in MI compared to controls [88]. Studies suggest that such reductions in CV risk are related to improvements in postprandial endothelial function $[89,90]$.

\section{Insulin}

Many patients with T2DM are often treated with insulin early in the disease process, in spite of the availability of multiple classes of antidiabetic agents with extremely low risks of hypoglycemia. Furthermore, with longer durations of diabetes and progressive $\beta$-cell deterioration, most patients with T2DM will eventually require insulin to control glucose levels effectively, and prevent diabetes-related complications. Direct insulin-related positive effects on the lipid profile include reductions in TG levels, most apparent with more dramatic improvement of glycemic control, along with increases in HDL-C levels; LDL-C levels remain typically unaffected $[44,91]$.

\section{Antihypertensive agents}

The latest guidelines from the US Eighth Joint National Committee (JNC 8) recommend the use of thiazide diuretics, angiotensin-converting enzyme (ACE) inhibitors, angiotensin receptor blockers (ARBs), or calcium antagonists as first-line treatment of patients with hypertension, including those with diabetes [92]. The JNC 8 guidelines do not include $\beta$-blockers as first-line treatment, but these agents have been widely used in the past, particularly in hypertensive patients with heart failure or with an increased risk of CHD [93].

\section{Thiazide diuretics and calcium antagonists}

Thiazide diuretics lead to dose-dependent increases in cholesterol levels without altering HDL-C levels [94, 95]. Despite this increase in cholesterol levels, diuretic-based antihypertensive treatment effectively reduced the risk of stroke, MI, and CHD in patients with diabetes in the Systolic Hypertension in the Elderly Program (SHEP) [96, 97].

Calcium antagonists do not appear to affect the lipid profile [94, 98], although some evidence suggests that they might enhance TG removal [99]. Results of the Antihypertensive and Lipid-Lowering Treatment to Prevent Heart Attack Trial (ALLHAT) showed a greater decrease of serum cholesterol in patients treated with calcium antagonists compared with diuretics [100].

\section{ACE inhibitors}

The available data on the effect of ACE inhibitors on lipid profiles are inconsistent. In the past, it was believed that ACE inhibitors had no effects on the lipid profile [101, 102]; however, newer data suggest that some ACE inhibitors could have favorable effects on the lipid profile and atherosclerotic changes [103], significantly lowering serum LDL-C and TG levels, and increasing HDL-C levels $[101,104]$.

\section{ARBs}

ARBs have been shown to significantly increase HDL-C levels and decrease LDL-C levels. In general, ARBs also tend to lower apo B levels, while only losartan and valsartan have been shown to significantly decrease TG levels [95]. Treatment with ARBs may therefore positively impact CVD risk through blood pressure reduction and positive effects on the plasma lipid profile [105]. 


\section{B-blockers}

Adverse effects associated with early $\beta$-blockers, such as negative effects on glycemic control, dyslipidemia, and masking of hypoglycemia, have long contributed to controversy around their use [93]. However, as $\beta$-blockers have evolved, some of these effects have changed. The first-generation $\beta 1$ - and $\beta 2$-nonselective adrenergic receptor blockers, such as propranolol and nadolol, have negligible effects on LDL-C levels, but increase TG levels and decrease HDL-C levels $[17,106]$; their use results in a shift to more atherogenic, smaller, denser LDL-P [41]. In the case of propranolol, none of the associated lipid changes were considered to be strongly predictive of coronary events or mortality [106]. Use of second-generation $\beta 1$-selective agents, such as atenolol and metoprolol, has been found to be associated with the development of fewer atherogenic particles [93].

Third-generation $\beta$-blockers, such as nebivolol and carvedilol, have beneficial vasodilatory properties [93]. Nebivolol, a $\beta 1$-selective blocker, stimulates endothelium-derived nitric oxide release [107] and has been shown to significantly reduce total cholesterol and LDL-C levels, and improve the LDL-C:HDL-C ratio, albeit with no significant changes in HDL-C or TG levels [108]. Carvedilol, a nonselective $\beta$ - and $\alpha 1$-blocker, has shown no meaningful effects on the lipid profile, only slightly decreasing TG levels $[107,109]$.

\section{Weight loss medications}

In studies, use of the gastrointestinal lipase inhibitor orlistat has consistently been associated with reductions in LDL-C levels, while TG and HDL-C levels have either been reduced or not significantly changed when compared with placebo [110-113]. No consistent changes have been observed with the use of the selective serotonin-2C RA lorcaserin; TG and LDL-C levels remained unchanged or showed a slight reduction, whereas HDL-C levels increased slightly in some cases [114-117].

The two weight loss combination therapies phentermine/topiramate and naltrexone/bupropion have shown similar effects on lipid levels. Both therapies have been associated with significant reductions in TG levels and increases in HDL-C levels. Phentermine/topiramate has also been shown to reduce LDL-C levels, while naltrexone/bupropion has been linked to a reduction or no change in LDL-C levels [118-128].

\section{Antibiotics}

Relatively few data exist on the effects of antibiotics on lipid levels, although some changes have been observed in small studies. Metronidazole has been associated with a significant reduction in LDL-C levels, while ciprofloxacin has been linked to an increase in HDL-C levels
$[129,130]$. In both cases, these effects were attributed to changes in the gastrointestinal flora as a result of antibiotic use.

\section{Analgesics}

Nonsteroidal anti-inflammatory drugs (NSAIDs), such as ibuprofen and naproxen, inhibit the activity of both cyclooxygenase-1 (COX-1) and -2 (COX-2) [131], whereas acetaminophen has been associated with selective COX-2 inhibition [132]. Although little information is available on the effects of these analgesics on the lipid profile, frequent use of NSAIDs or acetaminophen has been associated with a significantly increased risk of CV events [133], with nonaspirin (acetylsalicylic acid) NSAIDs increasing the chance of a heart attack or stroke. Aspirin is a more selective COX-1 inhibitor that has been shown to slightly decrease TG levels $[131,134]$ and have moderate benefits on CVD-related factors, reducing the risk of stroke but not CHD [131]. Excessive use of NSAIDs has been linked to acute CKD [135, 136]. Furthermore, CKD is associated with dyslipidemia, which can, in some settings, be profound [137]. According to the National Kidney Foundation (NKF) and The Alliance for Rational Use of NSAIDs, NSAIDs should not be used if there is decreased kidney function because they reduce the blood flow to the kidneys. Also, longterm NSAID use with higher doses may harm healthy kidneys. Kidney disease caused by NSAID use is preventable [138]. The US Food and Drug Administration (FDA) and the European Medicines Agency (EMA) have mandated regulatory language and strongly recommend that all NSAIDs should be administered at the lowest effective dose for the shortest period of time while taking into account patient-specific risk factors and clinical needs [139].

\section{Oral contraceptives and HRT}

According to the International Diabetes Federation (IDF), more than 10 million women in the United States are affected by diabetes [140]. Many oral contraceptives are associated with a negative impact on the lipid profile. Second-generation oral progestogen contraceptives (e.g. levonorgestrel) have been shown to increase LDL-C and TG levels (the latter sometimes profoundly), while decreasing HDL-C levels [17]. In contrast, third-generation progestogens (e.g. desogestrel) have no associated increase in ASCVD risk factors [17]. Although these contraceptives significantly increase TG levels, they also lead to a decrease in LDL-C levels and an increase in HDL-C levels due to slowing of HDL-C transport to the liver $[17,141]$. Depot medroxyprogesterone acetate (DMPA) increases LDL-C, decreases HDL-C, and has no effect on TG levels [142]. 
In combined oral contraceptive pills, the estrogen component typically mediates a decrease in LDL-C levels and an increase in HDL-C and TG levels, whereas the progestogen component increases LDL-C and decreases HDL-C and TG levels. The overall effect on the lipid profile leads to reduced levels of LDL-C and increased levels of HDL-C and TG [142].

In postmenopausal women with normal or elevated baseline lipid levels, oral estrogen monotherapy as HRT reduces LDL-C levels and increases HDL-C levels. In contrast, transdermal administration of $17 \beta$-estradiol has been found to have no effect on lipoprotein levels [143]. In women taking oral conjugated estrogen combined with DMPA, no CV benefit has been observed in large randomized clinical trials of primary [144] or secondary prevention $[145,146]$. The expected ASCVD benefit of oral combination HRT may have been offset by other effects, such as an increase in clotting factors and consequent elevated risk of thromboembolism.

\section{Other common medications}

Glucocorticoids, such as prednisone, are key therapies in the treatment of asthma and other inflammatory conditions. These drugs have been shown to increase LDL-C, HDL-C, and TG levels, and potentially cause hypertension, obesity, and insulin resistance. Thus, prolonged use of these medications can negatively impact the lipid profile and ASCVD risk factors [95, 147].

Vitamin D deficiency is associated with an unfavorable lipid profile in cross-sectional analyses, but correcting for a deficiency does not translate into clinically meaningful changes in lipid concentrations [148]. Vitamin B12 deficiency is also associated with unfavorable TG and cholesterol/HDL-C ratio in patients with T2DM, and such deficiency has been shown to increase the risk of comorbid coronary artery disease [149]. Ascorbic acid, a form of vitamin $C$, has been shown to decrease LDL-C levels, but has no effect on HDL-C or TG levels [150]. Dietary supplementation with oils high in polyunsaturated fatty acids (PUFAs) has been shown to have favorable effects on serum lipid profiles in patients with T2DM or metabolic syndrome [151].

\section{Conclusions}

Many medications widely prescribed for patients with T2DM influence, to varying degrees, selected components of the routine lipid profile (i.e. LDL-C, HDL-C, and TG levels) and, consequently, potentially the risk for ASCVD. While some effects may be significant, many medications are associated with relatively small changes in the lipid profile and are therefore unlikely to affect ASCVD risk by themselves. However, the cumulative effect in patients taking multiple medications may be significant and should not be overlooked. The net effects of these medications on the lipid profile, in addition to effects on other factors related to $\mathrm{CV}$ health, should be anticipated, and their overall potential impact on ASCVD risk should be considered. Therefore, clinicians can help to ensure optimal care and avoid putting patients at unnecessary risk by performing ongoing lipid-panel monitoring, taking into account potential effects of commonly prescribed medications. Ultimately, lifestyle recommendations and lipid-lowering agents are required to target atherogenic cholesterol and achieve the appropriate goals determined by the absolute risk for an individual, especially those with a relatively higher absolute risk (i.e. patients with diabetes).

\section{Abbreviations}

A1C: glycated hemoglobin; AACE: American Association of Clinical Endocrinologists; ACE: angiotensin-converting enzyme; AGl: a-glucosidase inhibitor; ALLHAT: Antihypertensive and Lipid-Lowering Treatment to Prevent Heart Attack Trial; apo B: apolipoprotein B; ARB: angiotensin receptor blockers; ASCVD: atherosclerotic cardiovascular disease; BAS: bile acid sequestrant; $C H D$ : coronary heart disease; CKD: chronic kidney disease; COX: cyclooxygenase; CV: cardiovascular; CVD: cardiovascular disease; DMPA: depot medroxyprogesterone acetate; DPP-4: dipeptidyl peptidase-4; ELIXA: Evaluation of Lixisenatide in Acute Coronary Syndrome; EMA: European Medicines Agency; FDA: US Food and Drug Administration; GLP-1: glucagon-like peptide-1; HDL-C: high-density lipoprotein cholesterol; HIV: human immunodeficiency virus; HRT: hormone replacement therapy; IDF: International Diabetes Federation; JNC 8: Eighth Joint National Committee; LDL-C: low-density lipoprotein cholesterol; LDL-P: low-density lipoprotein particle; LRC-CPPT: Lipid Research Clinics Coronary Primary Prevention Trial; MACE: major adverse cardiac events; MI: myocardial infarction; NKF: National Kidney Foundation; NLA: National Lipid Association; NSAID: nonsteroidal anti-inflammatory drug; PROactive: Prospective Pioglitazone Clinical Trial in Macrovascular Events; PUFA: polyunsaturated fatty acid; QR: quick release; RA: receptor agonist; SHEP: Systolic Hypertension in the Elderly Program; SGLT2: sodium glucose co-transporter 2; SPREAD-DIMCAD: Study on the Prognosis and Effect of Antidiabetic Drugs on Type 2 Diabetes Mellitus with Coronary Artery Disease; SU: sulfonylurea; T1DM: type 1 diabetes mellitus; T2DM: type 2 diabetes mellitus; TG: triglyceride; TZD: thiazolidinedione; UKPDS: United Kingdom Prospective Diabetes Study; VLDL: very-lowdensity lipoprotein.

\section{Author details}

${ }^{1}$ Diabetes/Lipid Management \& Research Center, 18821 Delaware St, Suite 202, Huntington Beach, CA 92648, USA. ${ }^{2}$ Division of Endocrinology, Diabetes, Metabolism, Department of Medicine, University of California, Irvine (UCI) School of Medicine, Irvine, CA, USA.

\section{Acknowledgements}

Medical writing and editorial support were provided by Sandrine Buisson, Ph.D., and Adriana Stan, Ph.D., of Excerpta Medica, and by Cherie Koch, Ph.D., of MedErgy, and was funded by Janssen Scientific Affairs, LLC.

\section{Competing interests}

PR serves as a consultant for Amarin, AstraZeneca, Eli Lilly, Merck, and SanofiRegeneron; is a speaker for AbbVie, AstraZeneca, Boehringer Ingelheim, GlaxoSmithKline, Janssen Pharmaceuticals, Kowa, Merck, and Takeda; and has received research grants from Amgen, AstraZeneca, Bristol-Myers Squibb, Boehringer Ingelheim, Dexcom, GlaxoSmithKline, Ionis (formerly ISIS) Pharma, Lexicon, Merck, Novo Nordisk, Orexigen, Pfizer, and Sanofi.

Received: 17 March 2016 Accepted: 14 June 2016

Published online: 14 July 2016 


\section{References}

1. World Health Organization. Cardiovascular diseases (CVDs). http://www. who.int/mediacentre/factsheets/fs317/en/. Accessed 10 May 2016.

2. Jellinger PS, Smith DA, Mehta AE, Ganda O, Handelsman Y, Rodbard HW, et al. American Association of Clinical Endocrinologists' guidelines for management of dyslipidemia and prevention of atherosclerosis. Endocr Pract. 2012:18:1-78.

3. Jacobson TA, Ito MK, Maki KC, Orringer CE, Bays HE, Jones PH, et al. National Lipid Association recommendations for patient-centered management of dyslipidemia: part 1-full report. J Clin Lipidol. 2015;9:129-69.

4. Brunzell JD, Davidson M, Furberg CD, Goldberg RB, Howard BV, Stein $\mathrm{JH}$, et al. Lipoprotein management in patients with cardiometabolic risk: consensus statement from the American Diabetes Association and the American College of Cardiology Foundation. Diabetes Care. 2008:31:811-22.

5. Lotufo PA, Gaziano JM, Chae CU, Ajani UA, Moreno-John G, Buring JE, et al. Diabetes and all-cause and coronary heart disease mortality among US male physicians. Arch Intern Med. 2001;161:242-7.

6. Hu FB, Stampfer MJ, Solomon CG, Liu S, Willett WC, Speizer FE, et al. The impact of diabetes mellitus on mortality from all causes and coronary heart disease in women: 20 years of follow-up. Arch Intern Med. 2001;161:1717-23

7. Fruchart JC, Davignon J, Hermans MP, Al-Rubeaan K, Amarenco P, Assmann G, et al. Residual macrovascular risk in 2013: what have we learned? Cardiovasc Diabetol. 2014;13:26.

8. Lind M, Svensson AM, Kosiborod M, Gudbjornsdottir S, Pivodic A, Wedel $\mathrm{H}$, et al. Glycemic control and excess mortality in type 1 diabetes. N Engl J Med. 2014:371:1972-82.

9. Tancredi M, Rosengren A, Svensson AM, Kosiborod M, Pivodic A, Gudbjornsdottir S, et al. Excess mortality among persons with type 2 diabetes. N Engl J Med. 2015;373:1720-32.

10. Di Angelantonio E, Kaptoge S, Wormser D, Willeit P, Butterworth AS, Bansal N, et al. Association of cardiometabolic multimorbidity with mortality. JAMA. 2015:314:52-60.

11. Naghavi M, Libby P, Falk E, Casscells SW, Litovsky S, Rumberger J, et al. From vulnerable plaque to vulnerable patient: a call for new definitions and risk assessment strategies: part I. Circulation. 2003;108:1664-72.

12. Libby P, Ridker PM, Hansson GK. Inflammation in atherosclerosis: from pathophysiology to practice. J Am Coll Cardiol. 2009;54:2129-38.

13. Barter PJ, Ballantyne CM, Carmena R, Castro CM, Chapman MJ, Couture $P$, et al. Apo B versus cholesterol in estimating cardiovascular risk and in guiding therapy: report of the thirty-person/ten-country panel. J Intern Med. 2006:259:247-58.

14. Cromwell WC, Otvos JD, Keyes MJ, Pencina MJ, Sullivan L, Vasan RS, et al. LDL particle number and risk of future cardiovascular disease in the Framingham Offspring Study_implications for LDL management. J Clin Lipidol. 2007;1:583-92.

15. Tenenbaum A, Klempfner R, Fisman EZ. Hypertriglyceridemia: a too long unfairly neglected major cardiovascular risk factor. Cardiovasc Diabetol. 2014:13:159.

16. Cromwell WC, Otvos JD. Heterogeneity of low-density lipoprotein particle number in patients with type 2 diabetes mellitus and low-density lipoprotein cholesterol <100 mg/dL. Am J Cardiol. 2006;98:1599-602.

17. Mantel-Teeuwisse AK, Kloosterman JM, Maitland-van der Zee AH, Klungel $\mathrm{OH}$, Porsius AJ, de Boer A. Drug-induced lipid changes: a review of the unintended effects of some commonly used drugs on serum lipid levels. Drug Saf. 2001;24:443-56

18. Stone NJ, Robinson JG, Lichtenstein AH, Bairey Merz CN, Blum CB, Eckel $\mathrm{RH}$, et al. $2013 \mathrm{ACC} / \mathrm{AHA}$ guideline on the treatment of blood cholesterol to reduce atherosclerotic cardiovascular risk in adults: a report of the American College of Cardiology/American Heart Association Task Force on Practice Guidelines. J Am Coll Cardiol. 2014;63:2889-934.

19. Reiner Z, Catapano AL, De Backer G, Graham I, Taskinen MR, Wiklund O, et al. ESC/EAS guidelines for the management of dyslipidaemias: the Task Force for the management of dyslipidaemias of the European Society of Cardiology (ESC) and the European Atherosclerosis Society (EAS). Eur Heart J. 2011;32:1769-818.

20. Siahmansur TJ, Schofield JD, Azmi S, Liu Y, Durrington PN, Soran H. Unintended positive and negative effects of drugs on lipoproteins. Curr Opin Lipidol. 2015;26:325-37.
21. Wannamethee SG, Shaper AG, Whincup PH, Lennon L, Sattar N. Impact of diabetes on cardiovascular disease risk and all-cause mortality in older men: influence of age at onset, diabetes duration, and established and novel risk factors. Arch Intern Med. 2011;171:404-10.

22. Reaven GM, Chen YD, Jeppesen J, Maheux P, Krauss RM. Insulin resistance and hyperinsulinemia in individuals with small, dense low density lipoprotein particles. J Clin Invest. 1993:92:141-6.

23. Ovalle F. Cardiovascular implications of antihyperglycemic therapies for type 2 diabetes. Clin Ther. 2011;33:393-407.

24. Harper CR, Jacobson TA. Managing dyslipidemia in chronic kidney disease. J Am Coll Cardiol. 2008;51:2375-84.

25. Bays HE, Jones PH, Brown WV, Jacobson TA. National Lipid Association Annual Summary of Clinical Lipidology 2015. J Clin Lipidol. 2014;8:S1-36.

26. Davidson MH, Ballantyne CM, Jacobson TA, Bittner VA, Braun LT, Brown AS, et al. Clinical utility of inflammatory markers and advanced lipoprotein testing: advice from an expert panel of lipid specialists. J Clin Lipidol. 2011:5:338-67.

27. Garber AJ, Abrahamson MJ, Barzilay Jl, Blonde L, Bloomgarden ZT, Bush MA, et al. Consensus statement by the American Association of Clinical Endocrinologists and American College of Endocrinology on the comprehensive type 2 diabetes management algorithm-2016 executive summary. Endocr Pract. 2016;22:84-113.

28. Expert Dyslipidemia Panel of the International Atherosclerosis Society Panel Members. An International Atherosclerosis Society Position Paper: global recommendations for the management of dyslipidemia-full report. J Clin Lipidol. 2014:8:29-60.

29. Garber AJ, Abrahamson MJ, Barzilay Jl, Blonde L, Bloomgarden ZT, Bush MA, et al. AACE/ACE comprehensive diabetes management algorithm. Endocr Pract. 2015;2015:1-28.

30. Handelsman Y, Bloomgarden ZT, Grunberger G, Umpierrez G, Zimmerman RS, Bailey TS, et al. American Association of Clinical Endocrinologists and American College of Endocrinology-clinical practice guidelines for developing a diabetes mellitus comprehensive care plan-2015. Endocr Pract. 2015:21:1-87.

31. Inzucchi SE, Bergenstal RM, Buse JB, Diamant M, Ferrannini E, Nauck M, et al. Management of hyperglycemia in type 2 diabetes, 2015: a patientcentered approach: update to a position statement of the American Diabetes Association and the European Association for the Study of Diabetes. Diabetes Care 2015:38:140-9.

32. Rena G, Pearson ER, Sakamoto K. Molecular mechanism of action of metformin: old or new insights? Diabetologia. 2013;56:1898-906.

33. Wulffele MG, Kooy A, de Zeeuw D, Stehouwer CD, Gansevoort RT. The effect of metformin on blood pressure, plasma cholesterol and triglycerides in type 2 diabetes mellitus: a systematic review. J Intern Med. 2004:256:1-14.

34. Zhang C, Gao F, Luo H, Zhang CT, Zhang R. Differential response in levels of high-density lipoprotein cholesterol to one-year metformin treatment in prediabetic patients by race/ethnicity. Cardiovasc Diabetol. 2015;14:79.

35. UK Prospective Diabetes Study (UKPDS) Group. Effect of intensive blood-glucose control with metformin on complications in overweight patients with type 2 diabetes (UKPDS 34). Lancet. 1998;352:854-65.

36. Hong J, Zhang Y, Lai S, Lv A, Su Q, Dong Y, et al. Effects of metformin versus glipizide on cardiovascular outcomes in patients with type 2 diabetes and coronary artery disease. Diabetes Care. 2013;36:1304-11.

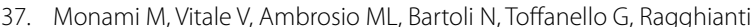
B, et al. Effects on lipid profile of dipeptidyl peptidase 4 inhibitors, pioglitazone, acarbose, and sulfonylureas: meta-analysis of placebocontrolled trials. Adv Ther. 2012:29:736-46.

38. Goldberg RB, Kendall DM, Deeg MA, Buse JB, Zagar AJ, Pinaire JA, et al. A comparison of lipid and glycemic effects of pioglitazone and rosiglitazone in patients with type 2 diabetes and dyslipidemia. Diabetes Care. 2005:28:1547-54

39. Samaha FF, Szapary PO, Iqbal N, Williams MM, Bloedon LT, Kochar A et al. Effects of rosiglitazone on lipids, adipokines, and inflammatory markers in nondiabetic patients with low high-density lipoprotein cholesterol and metabolic syndrome. Arterioscler Thromb Vasc Biol. 2006:26:624-30.

40. Szapary PO, Bloedon LT, Samaha FF, Duffy D, Wolfe ML, Soffer D, et al. Effects of pioglitazone on lipoproteins, inflammatory markers, and 
adipokines in nondiabetic patients with metabolic syndrome. Arterioscler Thromb Vasc Biol. 2006;26:182-8.

41. Superko HR, Haskell WL, Krauss RM. Association of lipoprotein subclass distribution with use of selective and non-selective beta-blocker medications in patients with coronary heart disease. Atherosclerosis. 1993;101:1-8

42. Austin MA, Breslow JL, Hennekens CH, Buring JE, Willett WC, Krauss RM. Low-density lipoprotein subclass patterns and risk of myocardial infarction. JAMA. 1988;260:1917-21.

43. Chait A, Brazg RL, Tribble DL, Krauss RM. Susceptibility of small, dense, low-density lipoproteins to oxidative modification in subjects with the atherogenic lipoprotein phenotype, pattern B. Am J Med. 1993;94:350-6.

44. Keidan B, Hsia J, Katz R. Plasma lipids and antidiabetic agents: a brief overview. Br J Diabetes Vasc Dis. 2002;2:40-3.

45. Stahli BE, Gebhard C, Tardif JC. Lipid effects and cardiovascular disease risk associated with glucose-lowering medications. Curr Cardiol Rep. 2015;17:608.

46. Dormandy JA, Charbonnel B, Eckland DJ, Erdmann E, Massi-Benedetti $\mathrm{M}$, Moules IK, et al. Secondary prevention of macrovascular events in patients with type 2 diabetes in the PROactive Study (PROspective pioglitAzone Clinical Trial In macroVascular Events): a randomised controlled trial. Lancet. 2005;366:1279-89.

47. Home PD, Pocock SJ, Beck-Nielsen H, Curtis PS, Gomis R, Hanefeld M, et al. Rosiglitazone evaluated for cardiovascular outcomes in oral agent combination therapy for type 2 diabetes (RECORD): a multicentre, randomised, open-label trial. Lancet. 2009;373:2125-35.

48. Roumie CL, Hung AM, Greevy RA, Grijalva CG, Liu X, Murff HJ, et al. Comparative effectiveness of sulfonylurea and metformin monotherapy on cardiovascular events in type 2 diabetes mellitus: a cohort study. Ann Intern Med. 2012;157:601-10.

49. Ferrannini E, Defronzo RA. Impact of glucose-lowering drugs on cardiovascular disease in type 2 diabetes. Eur Heart J. 2015;36:2288-96.

50. Drucker DJ. Enhancing incretin action for the treatment of type 2 diabetes. Diabetes Care. 2003;26:2929-40.

51. Choe EY, Cho Y, Choi Y, Yun Y, Wang HJ, Kwon O, et al. The effect of DPP-4 inhibitors on metabolic parameters in patients with type 2 diabetes. Diabetes Metab J. 2014;38:211-9.

52. Shigematsu E, Yamakawa T, Kadonosono K, Terauchi Y. Effect of sitagliptin on lipid profile in patients with type 2 diabetes mellitus. J Clin Med Res. 2014;6:327-35.

53. Takeda H, Sasai N, Ito S, Obana M, Takuma T, Takai M, et al. Efficacy and safety of alogliptin in patients with type 2 diabetes: analysis of the ATTAK-J study. J Clin Med Res. 2016:8:130-40.

54. Noguchi K, Hirota M, Miyoshi T, Tani Y, Noda Y, Ito H, et al. Single administration of vildagliptin attenuates postprandial hypertriglyceridemia and endothelial dysfunction in normoglycemic individuals. Exp Ther Med. 2015:9:84-8.

55. Noda Y, Miyoshi T, Oe H, Ohno Y, Nakamura K, Toh N, et al. Alogliptin ameliorates postprandial lipemia and postprandial endothelial dysfunction in non-diabetic subjects: a preliminary report. Cardiovasc Diabetol. 2013;12:8

56. Matikainen N, Manttari S, Schweizer A, Ulvestad A, Mills D, Dunning BE, et al. Vildagliptin therapy reduces postprandial intestinal triglyceriderich lipoprotein particles in patients with type 2 diabetes. Diabetologia. 2006:49:2049-57.

57. Tremblay AJ, Lamarche B, Deacon CF, Weisnagel SJ, Couture P. Effect of sitagliptin therapy on postprandial lipoprotein levels in patients with type 2 diabetes. Diabetes Obes Metab. 2011;13:366-73.

58. Derosa G, Bonaventura A, Bianchi L, Romano D, Fogari E, D'Angelo A, et al. Comparison of vildagliptin and glimepiride: effects on glycaemic control, fat tolerance and inflammatory markers in people with type 2 diabetes. Diabet Med. 2014;31:1515-23.

59. Dai $X$, Wang $H$, Jing Z, Fu P. The effect of a dual combination of noninsulin antidiabetic drugs on lipids: a systematic review and network meta-analysis. Curr Med Res Opin. 2014;30:1777-86.

60. Green JB, Bethel MA, Armstrong PW, Buse JB, Engel SS, Garg J, et al. Effect of sitagliptin on cardiovascular outcomes in type 2 diabetes. N Engl J Med. 2015:373:232-42.

61. Scirica BM, Bhatt DL, Braunwald E, Steg PG, Davidson J, Hirshberg B, et al. Saxagliptin and cardiovascular outcomes in patients with type 2 diabetes mellitus. N Engl J Med. 2013;369:1317-26.
62. White WB, Cannon CP, Heller SR, Nissen SE, Bergenstal RM, Bakris GL, et al. Alogliptin after acute coronary syndrome in patients with type 2 diabetes. N Engl J Med. 2013;369:1327-35.

63. Rotz ME, Ganetsky VS, Sen S, Thomas TF. Implications of incretin-based therapies on cardiovascular disease. Int J Clin Pract. 2015;69:531-49.

64. van Genugten RE, Moller-Goede DL, van Raalte DH, Diamant M. Extrapancreatic effects of incretin-based therapies: potential benefit for cardiovascular-risk management in type 2 diabetes. Diabetes Obes Metab. 2013;15:593-606.

65. Buse JB, Henry RR, Han J, Kim DD, Fineman MS, Baron AD. Effects of exenatide (exendin-4) on glycemic control over 30 weeks in sulfonylurea-treated patients with type 2 diabetes. Diabetes Care. 2004;27:2628-35.

66. Harris KB, McCarty DJ. Efficacy and tolerability of glucagon-like peptide-1 receptor agonists in patients with type 2 diabetes mellitus. Ther Adv Endocrinol Metab. 2015;6:3-18.

67. Blonde L, Pencek R, MacConell L. Association among weight change, glycemic control, and markers of cardiovascular risk with exenatide once weekly: a pooled analysis of patients with type 2 diabetes. Cardiovasc Diabetol. 2015;14:12.

68. Pfeffer MA, Claggett B, Diaz R, Dickstein K, Gerstein HC, Kober LV, et al. Lixisenatide in patients with type 2 diabetes and acute coronary syndrome. N Engl J Med. 2015;373:2247-57.

69. Zaccardi F, Webb DR, Htike ZZ, Youssef D, Khunti K, Davies MJ. Efficacy and safety of sodium-glucose cotransporter 2 inhibitors in type 2 diabetes mellitus: systematic review and network meta-analysis. Diabetes Obes Metab. 2016. doi:10.1111/dom.12670.

70. Rosenthal N, Meininger G, Ways K, Polidori D, Desai M, Qiu R, et al. Canagliflozin: a sodium glucose co-transporter 2 inhibitor for the treatment of type 2 diabetes mellitus. Ann NY Acad Sci. 2015;1358:28-43.

71. Matthaei S, Bowering K, Rohwedder K, Grohl A, Parikh S. Dapagliflozin improves glycemic control and reduces body weight as add-on therapy to metformin plus sulfonylurea: a 24-week randomized, double-blind clinical trial. Diabetes Care. 2015;38:365-72.

72. Häring HU, Merker L, Seewaldt-Becker E, Weimer M, Meinicke T, Broedl UC, et al. Empagliflozin as add-on to metformin in patients with type 2 diabetes: a 24-week, randomized, double-blind, placebo-controlled trial. Diabetes Care. 2014;37:1650-9.

73. Usiskin K, Kline I, Fung A, Mayer C, Meininger G. Safety and tolerability of canagliflozin in patients with type 2 diabetes: pooled analysis of phase 3 study results. Postgrad Med. 2014;126:16-34.

74. McGill JB. The SGLT2 inhibitor empagliflozin for the treatment of type 2 diabetes mellitus: a bench to bedside review. Diabetes Ther. 2014:5:43-63.

75. Zinman B, Wanner C, Lachin JM, Fitchett D, Bluhmki E, Hantel S, et al. Empagliflozin, cardiovascular outcomes, and mortality in type 2 diabetes. N Engl J Med. 2015;373:2117-28.

76. Staels B, Fonseca VA. Bile acids and metabolic regulation: mechanisms and clinical responses to bile acid sequestration. Diabetes Care. 2009;32(Suppl 2):S237-45.

77. Goldberg RB, Fonseca VA, Truitt KE, Jones MR. Efficacy and safety of colesevelam in patients with type 2 diabetes mellitus and inadequate glycemic control receiving insulin-based therapy. Arch Intern Med. 2008;168:1531-40.

78. Handelsman Y, Goldberg RB, Garvey WT, Fonseca VA, Rosenstock J, Jones MR, et al. Colesevelam hydrochloride to treat hypercholesterolemia and improve glycemia in prediabetes: a randomized, prospective study. Endocr Pract. 2010;16:617-28.

79. Rosenstock J, Rigby SP, Ford DM, Tao B, Chou HS. The glucose and lipid effects of colesevelam as monotherapy in drug-naive type 2 diabetes. Horm Metab Res. 2014;46:348-53.

80. Lipid Research Clinics Program. The Lipid Research Clinics Coronary Primary Prevention Trial results. II. The relationship of reduction in incidence of coronary heart disease to cholesterol lowering. JAMA. 1984;251:365-74.

81. DeFronzo RA. Bromocriptine: a sympatholytic, d2-dopamine agonist for the treatment of type 2 diabetes. Diabetes Care. 2011;34:789-94.

82. Vinik Al, Cincotta AH, Scranton RE, Bohannon N, Ezrokhi M, Gaziano $J M$. Effect of bromocriptine-QR on glycemic control in subjects with uncontrolled hyperglycemia on one or two oral anti-diabetes agents. Endocr Pract. 2012;18:931-43. 
83. Cincotta $\mathrm{AH}$, Meier AH, Cincotta JM. Bromocriptine improves glycaemic control and serum lipid profile in obese type 2 diabetic subjects: a new approach in the treatment of diabetes. Expert Opin Investig Drugs. 1999;8:1683-707.

84. Scranton R, Cincotta A. Bromocriptine-unique formulation of a dopamine agonist for the treatment of type 2 diabetes. Expert Opin Pharmacother. 2010:11:269-79.

85. Gaziano JM, Cincotta AH, Vinik A, Blonde L, Bohannon N, Scranton R. Effect of bromocriptine-QR (a quick-release formulation of bromocriptine mesylate) on major adverse cardiovascular events in type 2 diabetes subjects. J Am Heart Assoc. 2012;1:e002279.

86. van de Laar FA, Lucassen PL, Akkermans RP, van de Lisdonk EH, Rutten $\mathrm{GE}$, van Weel C. Alpha-glucosidase inhibitors for patients with type 2 diabetes: results from a Cochrane systematic review and meta-analysis. Diabetes Care. 2005;28:154-63.

87. Zhou J, Deng Z, Lu J, Li H, Zhang X, Peng Y, et al. Differential therapeutic effects of nateglinide and acarbose on fasting and postprandial lipid profiles: a randomized trial. Diabetes Technol Ther. 2015;17:229-34.

88. Chiasson J-L, Josse RG, Gomis R, Hanefeld M, Karasik A, Laakso M. Acarbose treatment and the risk of cardiovascular disease and hypertension in patients with impaired glucose tolerance: the STOP-NIDDM trial. JAMA. 2003:290:486-94.

89. Hiki M, Shimada K, Kiyanagi T, Fukao K, Hirose K, Ohsaka H, et al. Single administration of alpha-glucosidase inhibitors on endothelial function and incretin secretion in diabetic patients with coronary artery disease-Juntendo University trial: effects of miglitol on endothelial vascular reactivity in type 2 diabetic patients with coronary heart disease (J-MACH). Circ J. 2010;74:1471-8.

90. Kato T, Inoue T, Node K. Postprandial endothelial dysfunction in subjects with new-onset type 2 diabetes: an acarbose and nateglinide comparative study. Cardiovasc Diabetol. 2010;9:12.

91. Aslan I, Kucuksayan E, Aslan M. Effect of insulin analog initiation therapy on LDL/HDL subfraction profile and HDL associated enzymes in type 2 diabetic patients. Lipids Health Dis. 2013;12:54.

92. James PA, Oparil S, Carter BL, Cushman WC, Nison-Himmelfarb C, Handler J, et al. 2014 evidence-based guideline for the management of high blood pressure in adults: report from the panel members appointed to the Eighth Joint National Committee (JNC 8). JAMA. 2014;311:507-20

93. McGill JB. Reexamining misconceptions about $\beta$-blockers in patients with diabetes. Clin Diabetes. 2009;27:36-46.

94. Kasiske BL, Ma JZ, Kalil RS, Louis TA. Effects of antihypertensive therapy on serum lipids. Ann Intern Med. 1995;122:133-41.

95. Whayne TF, Mukherjee D. Medications not intended for treatment of dyslipidemias and with a variable effect on lipids. Curr Pharm Des. 2014;20:6325-38.

96. Ames RP. A comparison of blood lipid and blood pressure responses during the treatment of systemic hypertension with indapamide and with thiazides. Am J Cardiol. 1996:77:12b-6b.

97. Curb JD, Pressel SL, Cutler JA, Savage PJ, Applegate WB, Black H, et al. Effect of diuretic-based antihypertensive treatment on cardiovascular disease risk in older diabetic patients with isolated systolic hypertension. Systolic Hypertension in the Elderly Program Cooperative Research Group. JAMA. 1996;276:1886-92.

98. Grossman E, Messerli FH. Calcium antagonists. Prog Cardiovasc Dis. 2004:47:34-57.

99. Pasanisi F, Marotta T, Ferrara LA Gnasso A, Cortese C, Mancini M. Acute and chronic effects of dihydropyridines on triglycerides in humans. J Cardiovasc Pharmacol. 1988;12(Suppl 4):S140-1.

100. ALLHAT Officers and Coordinators for the ALLHAT Collaborative Research Group. Major outcomes in high-risk hypertensive patients randomized to angiotensin-converting enzyme inhibitor or calcium channel blocker vs diuretic: the Antihypertensive and Lipid-Lowering Treatment to Prevent Heart Attack Trial (ALLHAT). JAMA. 2002;288:2981-97.

101. Klein W. Antihypertensive therapy and modification of metabolic risk factors (glucose and lipid metabolism). Z Kardiol. 1992;81:295-302.

102. Zanchetti A. Overview and perspectives of antihypertensive treatment. Drugs. 1990;40(Suppl 4):85-91.

103. Gude D. Angiotensin-converting enzyme inhibitors in lipid metabolism and atherosclerosis: an ace up the sleeve? J Sci Soc. 2014:41:59-60.
104. Bitkin EC, Boyraz M, Taskin N, Akcay A, Ulucan K, Akyol MB, et al. Effects of ACE inhibitors on insulin resistance and lipid profile in children with metabolic syndrome. J Clin Res Pediatr Endocrinol. 2013;5:164-9.

105. Kyvelou SM, Vyssoulis GP, Karpanou EA, Adamopoulos DN, Zervoudaki Al, Pietri PG, et al. Effects of antihypertensive treatment with angiotensin II receptor blockers on lipid profile: an open multi-drug comparison trial. Hellenic J Cardiol. 2006:47:21-8.

106. Byington RP, Worthy J, Craven T, Furberg CD. Propranolol-induced lipid changes and their prognostic significance after a myocardial infarction: the Beta-Blocker Heart Attack Trial experience. Am J Cardiol. 1990;65:1287-91.

107. Bakris GL, Fonseca V, Katholi RE, McGill JB, Messerli FH, Phillips RA, et al. Metabolic effects of carvedilol vs metoprolol in patients with type 2 diabetes mellitus and hypertension: a randomized controlled trial. JAMA. 2004;292:2227-36.

108. Van Bortel LM. Efficacy, tolerability and safety of nebivolol in patients with hypertension and diabetes: a post-marketing surveillance study. Eur Rev Med Pharmacol Sci. 2010;14:749-58.

109. Ozbilen S, Eren MA, Turan MN, Sabuncu T. The impact of carvedilol and metoprolol on serum lipid concentrations and symptoms in patients with hyperthyroidism. Endocr Res. 2012;37:117-23.

110. Hollander PA, Elbein SC, Hirsch IB, Kelley D, McGill J, Taylor T, et al. Role of orlistat in the treatment of obese patients with type 2 diabetes. A 1-year randomized double-blind study. Diabetes Care. 1998;21:1288-94

111. Muls E, Kolanowski J, Scheen A, Van Gaal L. The effects of orlistat on weight and on serum lipids in obese patients with hypercholesterolemia: a randomized, double-blind, placebo-controlled, multicentre study. Int J Obes Relat Metab Disord. 2001;25:1713-21.

112. Torgerson JS, Hauptman J, Boldrin MN, Sjostrom L. XENical in the prevention of diabetes in obese subjects (XENDOS) study: a randomized study of orlistat as an adjunct to lifestyle changes for the prevention of type 2 diabetes in obese patients. Diabetes Care. 2004;27:155-61.

113. XENICAL ${ }^{\circledR}$ (orlistat) capsules for oral use [package insert]. South San Francisco: Genentech USA, Inc.; 2015.

114. $B E L V I Q{ }^{\circledR}$ (lorcaserin hydrochloride) tablets, for oral use [package insert]. Woodcliff Lake: Eisai Inc; 2012.

115. Fidler MC, Sanchez M, Raether B, Weissman NJ, Smith SR, Shanahan WR et al. A one-year randomized trial of lorcaserin for weight loss in obese and overweight adults: the BLOSSOM trial. J Clin Endocrinol Metab. 2011;96:3067-77.

116. O'Neil PM, Smith SR, Weissman NJ, Fidler MC, Sanchez M, Zhang J, et al. Randomized placebo-controlled clinical trial of lorcaserin for weight loss in type 2 diabetes mellitus: the BLOOM-DM study. Obesity (Silver Spring). 2012;20:1426-36.

117. Smith SR, Weissman NJ, Anderson CM, Sanchez M, Chuang E, Stubbe $S$, et al. Multicenter, placebo-controlled trial of lorcaserin for weight management. N Engl J Med. 2010;363:245-56.

118. CONTRAVE ${ }^{\circledR}$ (naltrexone $\mathrm{HCl}$ and bupropion $\mathrm{HCl}$ ) extended-release tablets [package insert]. Deerfield: Takeda Pharmaceuticals America, Inc.; 2014.

119. Greenway FL, Dunayevich E, Tollefson G, Erickson J, Guttadauria M, Fujioka K, et al. Comparison of combined bupropion and naltrexone therapy for obesity with monotherapy and placebo. J Clin Endocrinol Metab. 2009:94:4898-906.

120. Greenway FL, Fujioka K, Plodkowski RA, Mudaliar S, Guttadauria M, Erickson J, et al. Effect of naltrexone plus bupropion on weight loss in overweight and obese adults (COR-I): a multicentre, randomised, double-blind, placebo-controlled, phase 3 trial. Lancet. 2010:376:595-605

121. Hollander P, Gupta AK, Plodkowski R, Greenway F, Bays H, Burns C, et al. Effects of naltrexone sustained-release/bupropion sustained-release combination therapy on body weight and glycemic parameters in overweight and obese patients with type 2 diabetes. Diabetes Care. 2013:36:4022-9.

122. QSYMIA ${ }^{\circledR}$ (phentermine and topiramate extended-release) capsules, for oral use, CIV [package insert]. Mountain View: VIVUS, Inc.; 2014.

123. Wadden TA, Foreyt JP, Foster GD, Hill JO, Klein S, O'Neil PM, et al. Weight loss with naltrexone SR/bupropion SR combination therapy as an adjunct to behavior modification: the COR-BMOD trial. Obesity (Silver Spring). 2011;19:110-20. 
124. Christou GA, Kiortsis DN. The efficacy and safety of the naltrexone/ bupropion combination for the treatment of obesity: an update. Hormones (Athens). 2015;14:370-5.

125. Apovian CM, Aronne L, Rubino D, Still C, Wyatt H, Burns C, et al. A randomized, phase 3 trial of naltrexone SR/bupropion SR on weight and obesity-related risk factors (COR-II). Obesity (Silver Spring). 2013:21:935-43.

126. Garvey WT, Ryan DH, Look M, Gadde KM, Allison DB, Peterson CA, et al. Two-year sustained weight loss and metabolic benefits with controlledrelease phentermine/topiramate in obese and overweight adults (SEQUEL): a randomized, placebo-controlled, phase 3 extension study. Am J Clin Nutr. 2012;95:297-308.

127. Gadde KM, Allison DB, Ryan DH, Peterson CA, Troupin B, Schwiers $M L$, et al. Effects of low-dose, controlled-release, phentermine plus topiramate combination on weight and associated comorbidities in overweight and obese adults (CONQUER): a randomised, placebocontrolled, phase 3 trial. Lancet. 2011;377:1341-52.

128. Allison DB, Gadde KM, Garvey WT, Peterson CA, Schwiers ML, Najarian T, et al. Controlled-release phentermine/topiramate in severely obese adults: a randomized controlled trial (EQUIP). Obesity (Silver Spring). 2012;20:330-42

129. von Bergmann K, Streicher U, Leiss O, Jensen C, Gugler R. Serum-cholesterol-lowering effect of metronidazole and possible mechanisms of action. Klin Wochenschr. 1985;63:279-81.

130. Jenkins DJ, Kendall CW, Hamidi M, Vidgen E, Faulkner D, Parker T, et al. Effect of antibiotics as cholesterol-lowering agents. Metabolism. 2005;54:103-12.

131. Chan AT, Manson JE, Albert CM, Chae CU, Rexrode KM, Curhan GC, et al. Nonsteroidal antiinflammatory drugs, acetaminophen, and the risk of cardiovascular events. Circulation. 2006;113:1578-87.

132. Hinz B, Cheremina O, Brune K. Acetaminophen (paracetamol) is a selective cyclooxygenase-2 inhibitor in man. FASEB J. 2008;22:383-90.

133. Bhala N, Emberson J, Merhi A, Abramson S, Arber N, Baron JA, et al. Vascular and upper gastrointestinal effects of non-steroidal antiinflammatory drugs: meta-analyses of individual participant data from randomised trials. Lancet. 2013;382:769-79.

134. Henkin Y, Como JA, Oberman A. Secondary dyslipidemia. Inadvertent effects of drugs in clinical practice. JAMA. 1992;267:961-8.

135. Gooch K, Culleton BF, Manns BJ, Zhang J, Alfonso H, Tonelli M, et al. NSAID use and progression of chronic kidney disease. Am J Med. 2007;120:280-7

136. Michielsen $\mathrm{P}$, Heinemann $\mathrm{L}$, Mihatsch M, Schnulle $\mathrm{P}$, Graf H, Koch KM Non-phenacetin analgesics and analgesic nephropathy: clinical assessment of high users from a case-control study. Nephrol Dial Transplant. 2009;24:1253-9.

137. Tsimihodimos V, Dounousi E, Siamopoulos KC. Dyslipidemia in chronic kidney disease: an approach to pathogenesis and treatment. Am J Nephrol. 2008;28:958-73.

138. National Kidney Foundation and Alliance for Rational Use of NSAIDS. NKF and NSAID Alliance declares NSAID Awareness Week, August 24-28, 2015. https://www.kidney.org/news/nkf-and-nsaid-alliancedeclares-nsaid-awareness-week-august-24-\%E2\%80\%93-28. Accessed 13 May 2016.

139. US Food and Drug Administration. Public Health Advisory_FDA announces important changes and additional warnings for COX-2 selective and non-selective non-steroidal anti-inflammatory drugs (NSAIDs). http://www.fda.gov/Drugs/DrugSafety/PostmarketDrugSafetylnformationforPatientsandProviders/ucm150314.htm. Accessed 13 May 2016.
140. International Diabetes Federation. Women and diabetes. http://www idf.org/women-and-diabetes. Accessed 13 May 2016.

141. Berenson AB, Rahman M, Wilkinson G. Effect of injectable and oral contraceptives on serum lipids. Obstet Gynecol. 2009;114:786-94.

142. Armstrong C. ACOG releases guidelines on hormonal contraceptives in women with coexisting medical conditions. Am Fam Physician. 2007;75:1252-8.

143. Guetta V, Cannon RO III. Cardiovascular effects of estrogen and lipid-lowering therapies in postmenopausal women. Circulation. 1996;93:1928-37.

144. Rossouw JE, Anderson GL, Prentice RL, LaCroix AZ, Kooperberg C, Stefanick $M L$, et al. Risks and benefits of estrogen plus progestin in healthy postmenopausal women: principal results from the Women's Health Initiative randomized controlled trial. JAMA. 2002;288:321-33.

145. Grady D, Herrington D, Bittner V, Blumenthal R, Davidson M, Hlatky M, et al. Cardiovascular disease outcomes during 6.8 years of hormone therapy: Heart and Estrogen/progestin Replacement Study follow-up (HERS II). JAMA. 2002;288:49-57.

146. Hulley S, Grady D, Bush T, Furberg C, Herrington D, Riggs B, et al. Randomized trial of estrogen plus progestin for secondary prevention of coronary heart disease in postmenopausal women. Heart and Estrogen/progestin Replacement Study (HERS) Research Group. JAMA. 1998;280:605-13.

147. Walker BR. Glucocorticoids and cardiovascular disease. Eur J Endocrinol. 2007;157:545-59.

148. Ponda MP, Huang X, Odeh MA, Breslow JL, Kaufman HW. Vitamin D may not improve lipid levels: a serial clinical laboratory data study. Circulation. 2012;126:270-7.

149. Adaikalakoteswari A, Jayashri R, Sukumar N, Venkataraman H, Pradeepa R, Gokulakrishnan K, et al. Vitamin B12 deficiency is associated with adverse lipid profile in Europeans and Indians with type 2 diabetes. Cardiovasc Diabetol. 2014;13:129.

150. Abdollahzad H, Eghtesadi S, Nourmohammadi I, Khadem-Ansari M Nejad-Gashti H, Esmaillzadeh A. Effect of vitamin C supplementation on oxidative stress and lipid profiles in hemodialysis patients. Int J Vitam Nutr Res. 2009;79:281-7.

151. Lee TC, Ivester P, Hester AG, Sergeant S, Case LD, Morgan T, et al. The impact of polyunsaturated fatty acid-based dietary supplements on disease biomarkers in a metabolic syndrome/diabetes population. Lipids Health Dis. 2014;13:196.

152. Sharma MD. Role of saxagliptin as monotherapy or adjunct therapy in the treatment of type 2 diabetes. Ther Clin Risk Manag. 2010;6:233-7.

153. Salvetti A, Ghiadoni L. Thiazide diuretics in the treatment of hypertension: an update. J Am Soc Nephrol. 2006;17:S25-9.

154. Tziomalos K, Athyros VG, Karagiannis A, Mikhailidis DP. Dyslipidemia induced by drugs used for the prevention and treatment of vascular diseases. Open Cardiovasc Med J. 2011;5:85-9.

155. Zhang PY, Xu X, Li XC. Cardiovascular diseases: oxidative damage and antioxidant protection. Eur Rev Med Pharmacol Sci. 2014:18:3091-6.

\section{Submit your next manuscript to BioMed Central and we will help you at every step:}

- We accept pre-submission inquiries

- Our selector tool helps you to find the most relevant journal

- We provide round the clock customer support

- Convenient online submission

- Thorough peer review

- Inclusion in PubMed and all major indexing services

- Maximum visibility for your research

Submit your manuscript at www.biomedcentral com/submit 